\title{
Apoptosis and Activation-Induced Cell Death
}

\author{
Joaquín H. Patarroyo S. and Marlene I. Vargas V.
}

Additional information is available at the end of the chapter

http://dx.doi.org/10.5772/52805

\section{Introduction}

In 1885, Flemming reported the first morphological description of the natural process of cell death. This process is now known as apoptosis, a name that was chosen by Kerr [1] to describe the unique morphology associated with this type of cellular death, which is different from necrosis. After the initial description of apoptosis, it was recognized that this process occurs in all tissues as part of the normal cellular turnover. Apoptosis also occurs during embryogenesis, in which particular cells are 'programmed' to die, and hence the term 'programmed cell death' is used to describe this process.

Currently, cell death can be classified according to the morphological appearance of the lethal process (apoptotic, necrotic, autophagic or associated with mitosis), the enzymological criteria (with or without the involvement of nucleases or distinct classes of proteases, such as caspases or cathepsins), the functional aspects (programmed or accidental, physiological or pathological) or the immunological characteristics (immunogenic or non-immunogenic) [2,3].

Apoptosis is a genetically predetermined mechanism that may be elicited through a number of molecular pathways, the best characterized and most prominent of which are called the extrinsic and intrinsic pathways (Fig.1).

In the extrinsic pathway, which is also known as the "death receptor pathway", apoptosis is triggered by the ligand-induced activation of death receptors at the cell surface, which include the tumor necrosis factor (TNF) receptor-1, CD95/Fas (the receptor of CD95L/FasL), and the TNF-related apoptosis inducing ligand receptors-1 and -2 (TRAIL-R1/2). In the intrinsic pathway, which is also called the "mitochondrial pathway", apoptosis results from an intracellular cascade of events in which mitochondrial permeabilization plays a crucial role [4].

In vitro studies showed evidence that all animal cells constitutively express the proteins needed to undergo apoptosis [5,6]. Apoptosis is a process that involves a variety of signaling pathways that lead to multiple cellular changes throughout the cell death process $[7,8]$. 


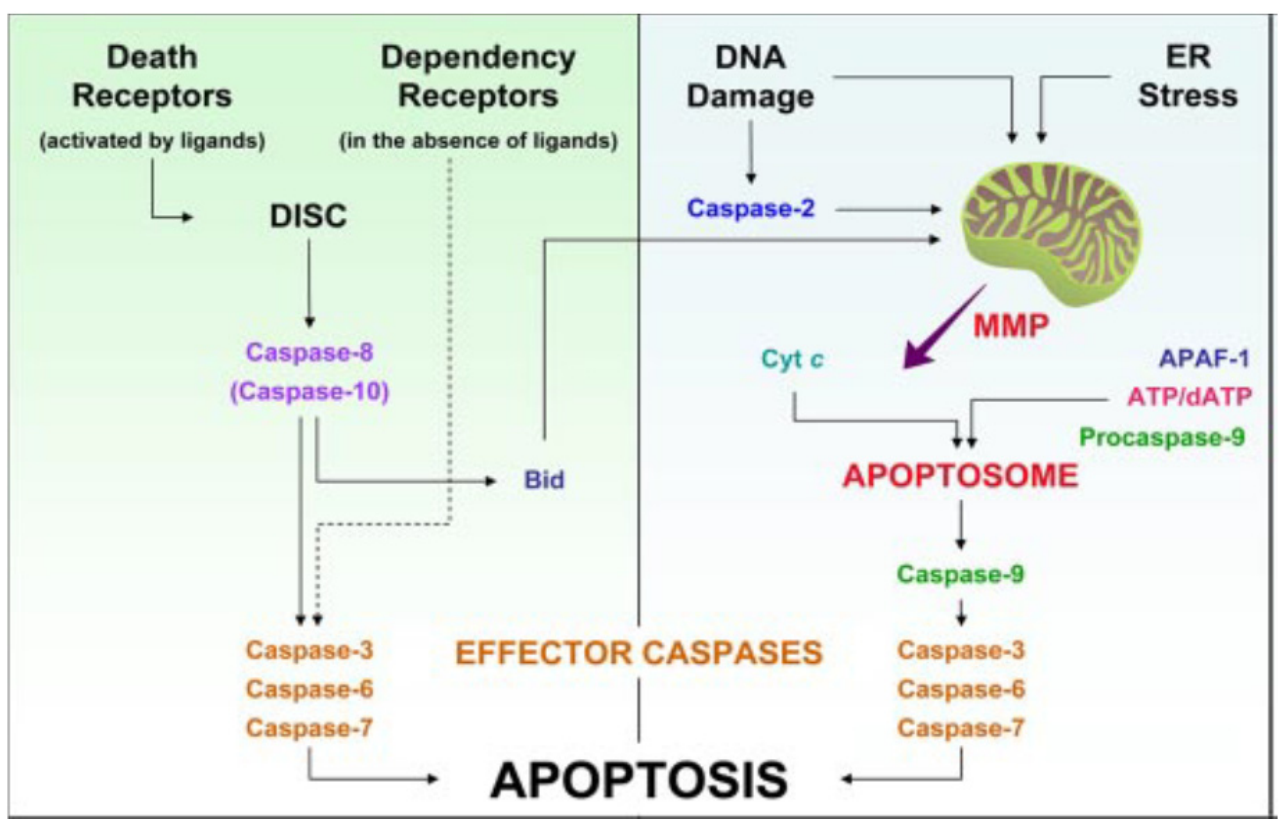

Figure 1. Extrinsic versus intrinsic caspase activation cascades. Left: extrinsic pathway. The ligandinduced activation of death receptors induces the assembly of the death-inducing signaling complex (DISC) on the cytoplasm side of the plasma membrane. This promotes the activation of caspase- 8 (and possibly of caspase-10), which in turn is able to cleave effector caspase-3, -6 , and -7 . Caspase- 8 can also proteolytically activate Bid, which promotes mitochondrial membrane permeabilization (MMP) and represents the main link between the extrinsic and intrinsic apoptotic pathways. The extrinsic pathway includes also the dependency receptors, which deliver a death signal in the absence of their ligands, through yet unidentified mediators. Right: intrinsic pathway. Several intracellular signals, including DNA damage and endoplasmic reticulum (ER) stress, converge on mitochondria to induce MMP, which causes the release of proapoptotic factors from the intermembrane space (IMS). Among these, cytochrome c (Cytc) induces the apoptosis protease-activating factor 1 (APAF-1) and ATP/dATP to assemble the apoptosome, a molecular platform which promotes the proteolytic maturation of caspase9. Active caspase-9, in turn, cleaves and activates the effector caspases, which finally lead to the apoptotic phenotype. DNA damage may signal also through the activation of caspase-2, which acts upstream mitochondria to favor MMP. Kroemer G, Galluzzi L, Brenner C. (2007).

The process of apoptosis has been conserved throughout evolution. Because of its conserved and uniform nature [8], apoptosis is frequently defined mechanistically as a pathway of regulated cell death that involves the sequential activation of caspases [Cysteine ASPartateSpecific ProteASEs], which are the major effectors of apoptosis [9]. Many caspases are present in healthy cells as catalytically dormant pro-enzymes [zymogens] that have very low enzymatic activity [10] but become activated at the onset of apoptosis through activation signals [11]. The proteolytic cascade in which one caspase can activate other caspases amplifies the apoptotic signaling pathway and thus leads to rapid cell death. However, not all caspases are required for apoptosis. In fact, the process generally requires 
the activation of a limited subset of caspases; in particular, caspases-3, -6, and -7 are the "executioner" caspases and these mediate their effects through the cleavage of specific substrates in the cell [12]. Over the last 10 years, intense research has focused on the pathways that control caspase activation. Some of these pathways, such as the apoptosome and death receptor-mediated pathways and the signalosomes responsible for caspase activation, are well established, whereas others are less clearly defined [12-14].

Other proteases, such as granzymes and calpain, are also involved in the apoptotic signaling process, but in a much more cell type- and/or stimulus-specific manner. At least three distinct caspase-signaling pathways exist: one is activated through the ligand-dependent death receptor oligomerization, the second through mitochondrial permeabilization, which leads to the release of proapoptotic proteins from the mitochondrial intermembrane space [15], and the third through stress-mediated events that involve the endoplasmic reticulum $[16,17]$. These pathways can also interact to amplify weak apoptotic signals. Some studies about programmed cell death indicate that apoptosis may occur in the complete absence of caspases; these instances include when organelles, such as the mitochondria, endoplasmic reticulum or lysosomes, are damaged leading to an increased release of calcium, species of oxygen free radicals and effectors proteins [18-20].

Formation of the death-inducing signaling complex (DISC) or the apoptosome activates initiator and common effectors caspases that execute the apoptosis process; both of these types of caspases are found in the cytoplasm. However, there is now evidence that the two pathways are linked and that molecules from one pathway can influence the other [16-24]. In addition, another mechanism activates a parallel caspase-independent cell death pathway via single stranded DNA damage [25].

\section{Apoptosis mechanisms and pathways}

Studies from the 1970s and 1980s have shown that apoptosis can be defined by specific morphological characteristics and is regulated by specific biochemical processes. Studies using the nematode Caenorhabditis elegans have contributed most of the current understanding of the apoptosis mechanisms [26,27]. The final phase of apoptosis is the activation of endonucleases, which leads to the fragmentation of DNA. Apoptosis is genetically predetermined and there are therefore genes that can promote or inhibit it [27]; these genes can respond to both normal and pathological stimuli.

Individual genes have been associated with apoptosis in two ways: the genes either are expressed in cells undergoing apoptosis or modulate the effects of the process. Among these, the proto-oncogene c-myc triggers either cell proliferation or apoptosis. Under normal conditions, this gene programs the cell to grow; however, if this procedure is prevented due to the lack of growth factors or the presence of secondary oncogenes, the cell enters the death process. The expression of c-myc is required for this process most likely because cmyc influences the delicate balance between the survival and death signaling pathways that are simultaneously activated by this factor [28]. 
The caspases are directly or indirectly responsible for the morphological and biochemical changes that characterize the process of apoptosis [29]. The machinery of cell death effectors that is managed by the family of caspases cleaves many vital proteins and proteolytically active enzymes, a process that contributes to the destruction of the cell. All caspases are initially synthesized as inactive zymogens that contain a prodomain that is formed by a p20 large subunit and a p10 small subunit. The activation of this zymogen precursor is mediated by a series of cleavage events, especially for the executioner caspases, which first separate the large and small subunits and then remove the prodomain. The active enzyme is composed of a heterotetramer that is formed by two large and two small subunits [30].

To date, 14 mammalian caspases have been identified. These can be subdivided into families based on their sequence homology and substrate specificity [31]. Caspases can be classified as: Caspase-1 (ICE), caspase-2 (ICH-1, Nedd-2), caspase-3 (CPP32, Apopain, Yama), caspase4 (ICH-2, TX, ICEre), caspase-5 (ICErel, TY), caspase-6 (Mch2), caspase-7 (ICE-LAP3, Mch3, CMH-1), caspase-8 (FLICE,Mch5, MACH), caspase-9 (Mch6, ICELAP6), caspase-10 (Mch4), caspase-11 (ICH-3), caspase-12, caspase-13 (ERICE) and caspase-14 (MICE) [6]. Currently, 11 human caspases have been identified: caspase- 1 through -10 and caspase- 14 [9,32,33]. The protein initially named caspase-13 was later found to represent a bovine homologue of caspase- 4 [34] and caspase- 11 and -12 are murine enzymes that are most likely the homologues of the human caspase- 4 and -5 . However, only some of these caspases have been found to be involved in the process of apoptosis; these are caspase-2, caspase-3, caspase-6, caspase-7, caspase-8, caspase-9, caspase-10 and caspase-12 [35].

Caspases can also be classified as either initiators or effectors. The upstream (initiator) caspases, unlike the downstream (effector) caspases, have long prodomains with structural motifs (e.g., death effector domain, DED, or caspase recruitment domain, CARD) that associate with their specific activators [36]. Any apoptotic extracellular or intracellular signal is transduced by adapter proteins and transmitted to specific cysteine proteases called "initiator caspases", which commit the cell to apoptosis. However, the activated caspases can be inhibited by endogenous inhibitors, such as IAPs (inhibitors of apoptosis). The commitment is followed by the "execution" of the cells through the sequential activation of the "executioner caspases" and the systematic disintegration of the cellular structure, which is followed by the disposal of the dead cells by phagocytosis. The adapter proteins include molecules that are homologous to the nematode protein CED-4, whereas initiator and executioner caspases are homologues of CED-3. Each of the initiator caspases and the respective adapter molecules, which are responsible for the oligomerization of the caspase to which it binds, define distinct pathways for apoptotic caspase activation and cell death [37].

The apoptotic signaling pathways that lead to zymogen processing can be subdivided into two major categories: cell surface or intracellular sensor-mediated. The former pathway is activated in response to extracellular signals, which indicate that the existence of the cell is no longer needed for the well-being of the organism. These cell surface sensor-mediated apoptotic signals are initiated by the binding of ligands to cell surface death-mediating receptors, which include the death receptor family [38]. 
During the past two decades, extensive work has been performed to elucidate the molecular mechanism of apoptosis. It is clear that apoptosis is induced by a range of stimuli that activate two major cell death signaling pathways: the intrinsic pathway, which is mainly controlled by the Bcl-2 protein family members, and the extrinsic pathway, which is activated by the death receptors of the tumor necrosis factor receptor superfamily.

The extrinsic pathway is triggered by death receptor engagement, which initiates a signaling cascade that is mediated by the activation of caspase- 8 . Specifically, apoptosis is induced by the interaction of a death receptor, namely, Fas (APO-1, CD95), TNF receptor-1 (TNFR-1), DR-3 (TRAMP), DR-4 (TRAIL-R1) or DR-5 (TRAIL-R2), with its respective ligand [39]. These cell surface receptors, which are located on the cell membrane, are members of the TNFR family. The binding of a ligand to a death receptor cause its oligomerization, which results in its activation. The oligomerization of the receptors is followed by the binding of specific adapter proteins (FADD, TRADD) to the receptor complex, which results in the recruitment of the procaspase- 8 and -10 to the receptor complex where the proenzymes become activated. Active caspase- 8 and -10 , in turn, active through effector caspase- 3 the caspase cascade [35]. The best-characterized ligands and their corresponding death receptors include FasL/FasR, TNF- $\alpha$ /TNFR1, Apo3L/DR3, Apo2L/DR4 and Apo2L/DR5 [40-43]. Alternatively, an extrinsic pro-apoptotic signal can be dispatched by the so-called 'dependence receptors', including netrin receptors (e.g., UNC5A-D and deleted in colorectal carcinoma, DCC). These receptors induce apoptosis in the absence of the required stimulus (when unoccupied by a trophic ligand, or possibly when bound by a competing 'antitrophin'), but block apoptosis following binding of their respective ligands [2,3].

The intrinsic pathway is activated when various apoptotic stimuli trigger the release of cytochrome $\mathrm{c}$ from the mitochondria, which is independent of caspase- 8 activation. This activation occurs through the formation of an "apoptosome", which consists of cytochrome c, the apoptotic protease activating factor-1 (Apaf-1) and procaspase- 9 . The formation of the apoptosome is dependent on both the release of cytochrome $c$ from the mitochondria and free ATP or dATP in the cell [42-45]. Together with ATP/dATP, cytochrome $c$ binds to Apaf1 , a cytosolic protein, and induces its oligomerization, which leads to the recruitment of an initiator caspase, procaspase-9, which undergoes a conformational change that results in caspase-9 activation. These proteins (adaptor proteins and procaspases) interact via their caspase recruitment domains (CARD). The apoptosome then recruits procaspase-3, which is subsequently cleaved, and therefore activated, by the active caspase- 9 and then released to mediate apoptosis. This mechanism is caspase-dependent; however, a caspase-independent cell death (CICD) pathway also exists. In this mechanism, the apoptosis-induced factor (AIF) and endonuclease $G$ (EndoG) are released from the mitochondria and relocate to the nucleus, where they mediate the large-scale fragmentation of DNA independently of caspases [46].

The mitochondrial outer membrane (MOM) permeabilization is considered the "point of no return" for apoptotic cell death and triggers the release of proteins that mediate cell death, such as cytochrome c, into the cytoplasm [46,47]. 
The intrinsic cell death signals generally converge within the cell at the MOM and result in the loss of mitochondrial membrane integrity and the subsequent activation of the downstream apoptotic pathways. The release of cytochrome $c$ and others proteins from the mitochondria is tightly regulated by pro-apoptotic members of the Bcl-2 family, which are believed to act as ion and/or protein channels or possibly as regulators of such channels $[14,15,19]$. The anti-apoptotic members of this family protect the cells from apoptosis through the sequestration of pro-apoptotic proteins or by interfering with their activities [48-50].

The DR (extrinsic) and mitochondrial (intrinsic) apoptosis pathways have been described in detail [51-57].

The pathway that is utilized depends on the initial death signal, the cell type involved, and the balance between pro-apoptotic and anti-apoptotic signals [58]. In addition, the initiation of a specific pathway may exhibit cross-talk with another, which might result in the activation of a second pathway. Although there is a wide variety of physiological and pathological stimuli and conditions that can trigger apoptosis, not all cells will necessarily die in response to the same stimulus.

Recent studies implicate the ER as a third sub-cellular compartment that can signal apoptosis via a signaling pathway that is called the ER-stress pathway [59]. Prolonged ER stress or the mobilization of intracellular $\mathrm{Ca}^{++}$stores stimulates the cleavage and activation of pro-caspase-12 (in mice), which is localized in the ER membrane, by $\mathrm{m}$ calpain. Once activated, caspase-12 then activates executioner caspases to induce apoptosis. Studies have shown that prolonged ER stress can result in the activation of caspase-12, which initiates apoptosis [56,60].

Several caspase regulators have been discovered, including activators and inhibitors of these proteases [22]. Inhibitor of apoptosis proteins (IAPs) interfere with apoptosis by blocking caspase activity. Therefore, because of their inhibitory activity against the executioner caspases, IAPs may inhibit all caspase-dependent apoptosis. However, Smac/DIABLO, a mitochondrial protein released in the cytosol in response to an apoptotic stimulus, inhibits the anti-apoptotic function of several members of the IAP family, thereby de-repressing caspase activation [61].

The intrinsic pathway is marked by a requirement for the involvement of mitochondria. Under the control of the BCL-2 family the mitochondria participate in apoptosis by releasing apoptogenic factors.

The Bcl-2 family members can be divided into three subfamilies based on their structural and functional features [62]. The anti-apoptotic subfamily contains the Bcl-2, Bcl-XL, Bcl-w, Mcl-1, Bfl1/A-1, and Bcl-B proteins. The members of this subfamily suppress apoptosis and contain all four Bcl-2 homology (BH) domains. Some pro-apoptotic proteins, such as Bax, Bak, and Bok, contain BH 1-3 domains and are therefore termed "multidomain" whereas other pro-apoptotic proteins possess only $\mathrm{BH} 3$ domain and are thus referred to as "BH3only" proteins [63]. 
The intrinsic pathway, which is also called the BCL-2-regulated or mitochondrial pathway (in reference to the role this organelle plays), is activated by various developmental cues or cytotoxic stimuli such as viral infection, DNA damage and growth factor deprivation, and is strictly controlled by the BCL-2 family of proteins [64]. This pathway predominantly leads to the activation of caspase-9 [65], although, at least in certain cell types, it can proceed in the absence of caspase- 9 or its activator, the apoptotic protease-activating factor-1 (Apaf1) [11]. The extrinsic, or DR pathway, is triggered by the ligation of the so-called death receptors, such as Fas or TNF-R1, which contain an intracellular death domain that associates with adaptor proteins that can recruit and activate caspase- 8 through their Fasassociates death domains (FADD; also known as MORT1). This activation of caspase-8 causes the subsequent activation of downstream caspases, such as caspase- $3,-6$ or -7 , and does not necessarily involve the BCL-2 protein family $[64,66]$.

\section{Physiological cell death in the immune system}

In the immune system, the death of $\mathrm{T}$ and $\mathrm{B}$ lymphocytes induced by specific receptors may occur in the central and peripheral lymphoid compartments. Apoptosis is the most common form of cell death in the immune system [67].

Apoptosis occurs in the primary lymphoid organs, such as the bone marrow, the liver and the thymus, and is used to eliminate useless precursor cells with non-rearranged, or aberrantly rearranged, non-functional receptors. Furthermore, apoptosis is essential for the deletion of autoreactive $\mathrm{T}$ cells in the thymus and is therefore crucial in the assurance of central self-tolerance [68,69].

A similar apoptotic deletion mechanism operates in the T and B cells that are located in the peripheral lymphoid organs, such as the lymph nodes and the spleen. This cell deletion by apoptosis is another safeguard of the immune system to assure self-tolerance and to downregulate an excessive immune response. Lymphocytes that escape this process probably replenish the pool of cells that determine immunological memory [70-73].

\section{Antigenic stimulation drives proliferation and death}

The immune system has, among other characteristics, its specificity: the repertoire of $\mathrm{T}$ and B lymphocytes, initially built from randomly selected antibody and T cell receptor (TCR) variable region genes, is shaped by selection to cope, on the one hand, with the vast universe of antigens and, on the other hand, with the danger of autoimmunity [74]. Another distinctive feature is the control of homeostasis; after a clonal expansion phase, the antigenreactive lymphocytes must be deleted until the pool of lymphoid cells reaches its baseline level. This controlled cell death is achieved by a fine-tuned balance between growth/expansion and apoptotic death; in general, because the immune system produces more cells than it needs, the extra cells are eliminated by apoptosis [75].

The thymocytes that do not express a functional TCR die due to the lack of survival signals, an event that is known as "death by neglect". In contrast, thymocytes bearing a TCR that 
recognizes self-peptides that are presented by major histocompatibility complex (MHC) molecules are eliminated by apoptosis in response to a high-affinity signal; this process is termed negative selection [76,77]. Moreover, the normal immune response requires the regulated elimination of specific cell populations by apoptosis. During the development of $\mathrm{T}$ cells in the thymus and B cells in the bone marrow, all potentially autoreactive lymphocytes are removed by apoptosis. Therefore, the initial overproduction is followed by the death of those cells that fail to exhibit productive antigen specificities [49]. In addition, after the inciting antigen in an immune response has been cleared, cell death mechanisms return the number of lymphocytes to its normal physiological range.

Only those lymphocytes bearing an antigen receptor with an appropriate specificity are selected for survival and further differentiation; the remaining ( $75 \%$ and $\sim 95 \%$ of B-cell and T-cell precursors, respectively) undergo apoptosis [78-81].

The immature precursor $\mathrm{T}$ lymphocytes develop into mature antigen-reactive $\mathrm{T}$ cells in the thymus. The maturation process is associated with the acquisition of high expression levels of the TCR-CD3 complex and with tolerance to self antigens; these two characteristics are the consequence of positive and negative selection, respectively. Positive selection ensures the survival of immature $\mathrm{T}$ cells $\left(\mathrm{CD} 4^{+} \mathrm{CD} 8^{+}\right)$that have an appropriate TCR $[53,82]$.

The number of $\mathrm{T}$ cells that leave the thymus and enter the peripheral $\mathrm{T}$-cell pool is approximately $2-3 \%$ of the number of cells that were initially generated. The pre-T lymphocytes in the thymus undergo differentiation and TCR rearrangement. Those T cells that fail to rearrange their TCR genes productively and thus cannot be stimulated by selfMHC-peptide complexes die by neglect. In contrast, cells with autoreactive receptors are killed by activation-induced death [83].

Those thymocytes that successfully pass the pre-TCR selection develop into $\mathrm{CD} 4^{+} \mathrm{CD} 8^{+} \mathrm{T}$ cells and undergo further TCR-affinity-driven positive and negative selection. After these selection processes, the mature single-positive CD4+ MHC class-II restricted and CD8+ MHC class-I-restricted T cells leave the thymus and generate the peripheral T-cell pool [52].

There exists evidence for the positive selection of B cells based on B cell antigen receptor [BCR] specificity but the nature of the selecting ligands is not yet known. The processes of antigen receptor gene rearrangement and diversification can produce self-antigen specific $B$ and T lymphoid cells that could initiate autoimmune tissue destruction [11].

Apoptosis also occurs as a defense mechanism in immune reactions or when cells are damaged by disease or noxious agents [84]. During infection, the lymphocytes and other cells of the innate immune system, which express receptors that recognize foreign antigens, undergo proliferation and differentiation to develop effectors functions that help kill the invading pathogens. These effectors functions, which include cellular- or antibody-mediated cytotoxicity and inflammatory cytokines, can be harmful to the host. Therefore, to limit the damage to healthy tissue, mechanisms, such as cell inactivation and cell death, have evolved to shut down these immune responses [85]. 


\section{Activation-induced cell death}

The term "activation-induced cell death" (AICD) describes the signal-induced programmed cell death of $\mathrm{T}$ lymphocytes [86] and distinguishes this phenomenon, or apoptosis process, from other possible effects of antigen receptor ligation (e.g., cytokine production and clonal expansion). However, apoptosis via AICD is almost certainly a major mechanism of clonal deletion in the immune system.

The AICD process is induced by the same signals that, in other circumstances, can lead to T cell proliferation and activation; these signals include antigen recognition, the binding of an antibody anti CD3 and the exposure to mitogens [87]. The AICD may occur in immature or transformed T cells, as well as in mature and activated peripheral blood T cells [88-94].

The primary function of $\mathrm{T}$ lymphocytes is to mount an efficient immune response to an antigen. However, the maintenance of $\mathrm{T}$ lymphocyte homeostasis between antigenic challenges is also essential. Co-stimulatory molecules are required for efficient $\mathrm{T}$ cell responses and an IL-7 signal is essential for maintaining the homeostasis of both naïve and memory $\mathrm{T}$ cell populations. Both the intrinsic and the extrinsic apoptotic pathways are actively involved in the regulation of $\mathrm{T}$ cell responses and homeostasis. Several antiapoptotic molecules have been identified as critical effectors molecules in mature $\mathrm{T}$ lymphocytes and the co-stimulatory molecules signaling pathways [95].

The proliferation and differentiation of T- and B-cells following antigen stimulation are crucial in the adaptive immune response. In fact, the activation of $\mathrm{T}$ cells is a critical step that occurs early in the adaptive immune response.

The TCR is a transmembrane protein that consists of a heterodimer, which can be one of two types. In $95 \%$ of $\mathrm{T}$ cells, the heterodimer consists of an alpha $(\alpha)$ and a beta $(\beta)$ chain, which are expressed on the surface of T lymphocytes as part of a multi-subunit complex with the CD3 protein; in 5\% of T cells, however, the heterodimer consists of gamma and delta $(\gamma / \delta)$ chains. When the TCR engages with the antigen that is presented on the MHC, the T lymphocyte is activated through a series of biochemical events that are mediated by a number of enzymes, co-receptors, accessory molecules, and activated or released transcription factors. The $\alpha \beta$ chains of the TCR are joined by disulfide bonds and have a structure similar to immunoglobulins with an extracellular domain, which is responsible for the recognition of the antigenic peptide, a transmembrane domain and a short intracytoplasmatic domain $[96,97]$.

The induction of apoptosis via signaling through DR requires the close proximity of the intracytoplasmatic or transmembrane domain of several receptor molecules because their activation requires the cross-linking of several receptors [98-100].

Antigen-presenting cells (APCs) are specialized white blood cells that help fight off foreign substances that enter the body. Enzymes inside the APCs break down the antigen into smaller particles. The processed antigens are transported to the surface of the APCs, bound with either an MHC class I or class II molecule. This complex forms epitopes (part of a 
foreign substance that can be recognized by the immune system), which the TCR recognizes and binds to.

Two signals derived from the APCs are required for the activation-induced proliferation of $\mathrm{T}$ cells. The first signal is the engagement of the TCR to the MHC-antigen complex on the APC and the second involves the coupling of co-stimulatory molecules, such as CD28, on the $\mathrm{T}$ cell with the $\mathrm{B} 7$ protein family expressed by the APCs. The signaling pathways downstream of the TCR and CD28 involve the integration of complex signals that lead to activation, proliferation, cell survival, and death. These signals are all mediated by cell surface receptor-ligand interactions and cytokines, such as interleukin IL-2, IL-4, and IL-10, which are produced by accessory cells as well as the responding $\mathrm{T}$ cells themselves [101].

The CD3 protein complex, which is composed of five polypeptides $(\gamma \delta, \varepsilon, \zeta, \eta)$, is noncovalently associated with the TCR. Of the polypeptides, $90 \%$ the $\zeta$ chains form homodimers and $10 \%$ heterodimers with the $\eta$ chains. The remaining three polypeptides associate to form the heterodimers $\varepsilon \delta$ and $\varepsilon \gamma$, which are also transmembrane proteins with an intracytoplasmatic domain that is larger than the TCR $\alpha \beta$ and is responsible for translating the activation signals through the complex to the inside of the cell [102]. The TCR, the $\zeta$ chain, and the CD3 molecules comprise the TCR complex. The in vitro stimulation of T cells with anti-CD3 antibody induces a signaling response that stimulates the activity of protein tyrosine kinase (PTK) within seconds [103]. The first event leads to a series of biochemical exchanges that occur over a period of many hours; these include the expression of cytokine receptors, the secretion of cytokines, the initiation of DNA replication and the acquisition of a differentiated phenotype $[7,104]$.

The intracellular tails of the CD3 molecules contain a single conserved motif known as the immunoreceptor tyrosine-based activation motif (ITAM), which is essential for the signaling capability of the TCR. The PTK activity that is induced by the binding of a ligand to the TCR initiates the phosphorylation of tyrosine residues on a number of soluble and membraneassociated substrates. The activation of the ITAMs causes it to act as the substrate for PTK and recruits this protein to the TCR $[105,106]$.

TCR engagement by antigens triggers the tyrosine phosphorylation of the ITAMs, present in the TCR-CD3 complex. Such ITAMs function by orchestrating the sequential activation of the Src-related PTKs: Lck and Fyn, which initiate TCR signaling, followed by that of ZAP70, which further amplifies the response. Lck is activated by the interaction of MHC-II and CD4 or CD8. These various PTKs induce tyrosine phosphorylation of several polypeptides, including the transmembrane adaptor linker activator for T-Cells (LAT). Protein tyrosine phosphorylation subsequently leads to the activation of multiple pathways, including extracellular signal regulated kinase (ERK), c-Jun N-terminal kinase (JNK), nuclear factor kappa B and nuclear factor of activated T-Cells (NF- $\kappa B$ and NFAT) pathways, which ultimately induce effectors functions [105].

The AICD in peripheral $\mathrm{T}$ cells depends on the activation state of the cell, i.e., recently activated $\mathrm{T}$ cells are resistant to the induction of apoptosis and this initial resistance is followed by a subsequent sensitive phenotype. 
The AICD occurs by either a suicidal or fratricidal mechanism through the activation, after TCR stimulation, of either Fas or TNF-R2, respectively. The importance of the Fas/FasL system for the activation of AICD was demonstrated by the discovery of a soluble receptor called decoy receptor 3 (DcR3) which is a member of TNFR superfamily. It has been shown to be the decoy receptor for FasL, which inhibits FasL-mediated apoptosis [75].

Expression of FasL is restricted to the lymphoid organs, and defects in its expression are associated with pathophysiological and autoimmune disorders. The consequences of FasL shedding are quite substantial because only membrane-bound FasL (mFasL) triggers the death signal [106].

The TNF receptor family can also transduce signals via intermediary molecules that can lead, in some instances, to apoptosis via the activation of FADD and FLICE, which also mediate death signals from CD95 [54,108-112].

The first role described for the FADD protein was its interaction with the membrane-bound DRs, which leads to the hypothesis that it is cytoplasmic and only implicated in death signaling pathways. However, new evidence shows that FADD is a much more complex molecule. Depending on its phosphorylation state and subcellular localization, the FADD protein can induce apoptosis, survival, cell cycle progression or T cell proliferation [113].

During development and maturation, lymphocytes with antigen receptors that are not properly rearranged, not positively selected or potentially self-reactive die by apoptosis. Similarly, immature cells that are not selected to enter the pool of mature circulating cells and peripheral cells that exert reactivity for self-antigens undergo apoptosis [92].

Several cells types are involved in the immune response. First, the B and T lymphocytes recognize antigen. After antigen binding to their antigen-specific receptors, these cells undergo clonal expansion and differentiation into effectors cells [114].

The developing lymphocytes express antigen receptors of random specificity. If, within a given window of time, the antigen receptors in the lymphocyte are ligated, the cell is deleted, which might occur through elimination or functional deletion by permanent unresponsiveness. If this ligation does not occur, the cell may mature and subsequently bind to the antigenic stimulus, thereby driving the immune response. The process of clonal deletion in the regulation of central tolerance is now well established [50]. The first unambiguous demonstrations of this process occurred with observations of negative selection, in which developing $\mathrm{T}$ lymphocytes in the thymus that expressed antigen receptors disappeared from the T-cell pool.

The regulation of the life and death of $\mathrm{T}$ cells uses molecular mechanisms that may be different in distinct T-cell populations depending on their activation state [115].

\section{Dynamics of the immune response in peripheral lymphoid organs}

The induction of immunity occurs almost exclusively in the secondary lymphoid organs. Consequently, the examination of the lymphoid tissues allowed the elucidation of many of the steps that are involved in the generation of immunity. 
In secondary lymphatic tissues, which are the primary locations for the generation of the humoral immune response, the coordinated trafficking of the immune cells is maintained through the direct interaction of the APCs with the T and B cells, which lead to the germinal center formation, the immunoglobulin class switching and the affinity maturation processes of the antibody response [116]. The antigens arrive at the lymph nodes by way of the lymph as soluble antigens, immune complexes or in association with dendritic cells (DCs). The systemic antigens and immune complexes reach the spleen and are first encountered by B cells, macrophages and DCs in the marginal zone (MZ).

The site of B cell differentiation in response to antigen is the germinal center (GC). These structures, which arise within follicles, are responsible for the formation of long-lived memory via the long-lived circulating memory B cells and the long-lived plasma cells that typically reside in the bone marrow [117]. The GC has specific kinetics of expansion, contraction and ultimately dissolution. There is considerable proliferation and cell death within the GC, in addition to cell emigration from the GC [118].

In addition to soluble antigens transport into follicles, molecules smaller than 70-80 kDa are transported through the enclosed compartment of the reticular network, known as the conduit system, into the lumen of the high endothelial venules (HEV). The conduit system of the reticular network is a highly specialized extracellular matrix consisting of a central core, which is formed by interstitial matrix molecules, such as collagen type I and collagen type III. It is also surrounded by a basement membrane-like structure and is ensheathed by a layer of fibroblastic reticular cells [119].

The antigen presentation to B cells by DCs has been described by several groups and it is possible that outer T zone DCs present conduit-derived antigens to B cells. The conduits are also present within follicles but their contribution to antigen delivery within the follicles is not known.

The deletion of B cells that recognize autoantigens occurs at both the immature B cell stage in the bone marrow and the mature B cell stage in the lymph nodes and the spleen. The critical events of B-cell activation, proliferation, differentiation and apoptosis occur in the GCs of the lymphoid follicles. A significant number of B cells die during passage through the GC and the apoptotic B cells are rapidly cleared from this area [120].

The B cells that arrive at the lymph nodes via HEV in the T-zone might encounter antigenbearing DCs during their migration. Alternatively, follicular B cells that migrate through the B-T boundary region during their random walk might engage the DCs that are concentrated in this region [117].

The production of clusters of antibody secreting cells (ASC) is an important initial component of the $\mathrm{B}$ cell response to antigen. It occurs during both $\mathrm{T}$ cell-dependent and $\mathrm{T}$ cell-independent responses [121]. Furthermore, it has been determined that, depending on the route of antigen delivery, different types of B cells may be involved in focus formation. For example, particulate antigens that are delivered through the blood will, upon entry into 
the spleen, specifically activate MZ-B cells [122], whereas antigens that are delivered subcutaneously will activate follicular B cells through a complex process of antigen acquisition and B cell trafficking [123].

Apoptotic B cells are found throughout the GCs. Most of the apoptotic B cells, however, are located in the light zone, an area to which B cells from the dark zone immigrate. The dark zone is the site where most of the proliferation of germinal center B cells occurs [118]. Some of the dark zone B cells, termed centroblasts, express CD77 antigen. The CD77 molecule defines a B lymphocyte maturation pathway, specific for GC, where the cells undergo programmed cell death [124]. The apoptosis of germinal center B cells may be a consequence of a lack of stimulation through their cell surface Ig [125]. This lack of stimulation may lead to either affinity maturation, the process by which B cells produce antibodies with increased affinity for an antigen during an immune response, or to a decreased affinity for the immunizing antigen. Thus, B cells with functional receptors are positively selected and differentiate either towards B cell memory or plasma cells [126,127]. Within the lymphoid follicle, APO1/Fas are highly expressed in the areas where B-cell apoptosis occurs [128]. Bcl2 was shown to mediate an important survival signal for B cells and is believed to be involved in the maintenance of B-cell memory in GCs. The lack of Bcl-2 expression in areas where B cells die by apoptosis probably enables the cells to undergo apoptosis. On the other hand, overexpression of Bcl-2 in these cells would probably inhibit apoptosis $[129,130]$. There is evidence that the release of apoptogenic molecules from the mitochondria is not necessary for the induction of this pathway [131].

The CD40 receptor can mediate both pro- and anti-apoptotic signals. The binding of the CD40 ligand to its receptor can inhibit the apoptosis of B cells that are stimulated through their Ig receptors and can stimulate B cell proliferation and isotype switching. However, the same receptor-ligand interaction can also induce the expression of CD95 and therefore enhance the susceptibility of the B cell to CD95-mediated death [132].

In peripheral $\mathrm{T}$ cells, the triggering of the TCR has several consequences: first, primary activation of resting $\mathrm{T}$ cells via the TCR may lead to proliferation of the T-cell population; second, in the absence of co-stimulatory signals, TCR triggering may cause anergy; and, finally, TCR triggering of previously activated T cells may lead to apoptosis unless the T cells are rescued by additional signals [133-135].

Whereas the activation of naïve $\mathrm{T}$ cells results in their clonal expansion and differentiation, the repeated stimulation of previously activated cells with antigen triggers AICD, which can be prevented by blocking the FasL/Fas interaction. In addition, the AICD is associated with an activation-induced surface appearance of FasL, which, in turn, triggers death via Fas in an autocrine or paracrine fashion [53]. Therefore, most $\mathrm{T}$ cells become susceptible to the induction of apoptosis during their proliferation. This sensitization of $\mathrm{T}$ cells is achieved by the regulation of the extrinsic and the intrinsic apoptotic pathways and is influenced by Tcell-associated IL-2 [136], which, in this context, acts as a sensitizer to AICD apoptosis rather than as a growth factor [137]. The molecular mechanism by which this T cell sensitization is 
achieved involves the altered expression of genes that encode proteins such as BCL-2 family members, hematopoietic progenitor kinase 1 (HPK1), cellular FLICE-like inhibitory protein (cFLIP) family members and CD95L [138,139].

The AICD process involves the stimulation of CD95 [53,99,108], TNFR1 [139], TRAILR in 'helpless' memory CD8 T cells [140-144]. Some findings suggest that TNF is involved in the late phase of AICD [41].

In recent years, our research has focused on the development of a vaccine against Riphicephalus (Boophilus) microplus. Using the natural host as experimental model, the kinetics of the immune response in two peripheral lymphoid organs, the spleen and lymph nodes were studied. We performed a kinetic analysis of the apoptotic activity that occurs within the GCs of the draining lymph nodes of animals immunized with a synthetic vaccine after a primary and a secondary stimulation (Fig.2). The examination of the draining lymph nodes of the immunized bovines showed that the apoptosis in the GC occurred mainly in the dark zone seven days after immunization [146]. In parallel, we analyzed the in vitro immune memory and $\mathrm{AICD}$ of $\mathrm{CD}^{+} \mathrm{T}$ cells after stimulation with various inducers (mitramicina and cycloheximide) or inhibitors (benzimide riboside and cyclosporine A) and the synthetic vaccine. The AICD induced by the peptide was mediated by a calcineurinindependent pathway. However, we observed the induction of cell death after stimulation of the TCR by the increased expression of Fas, which is characteristic of AICD.
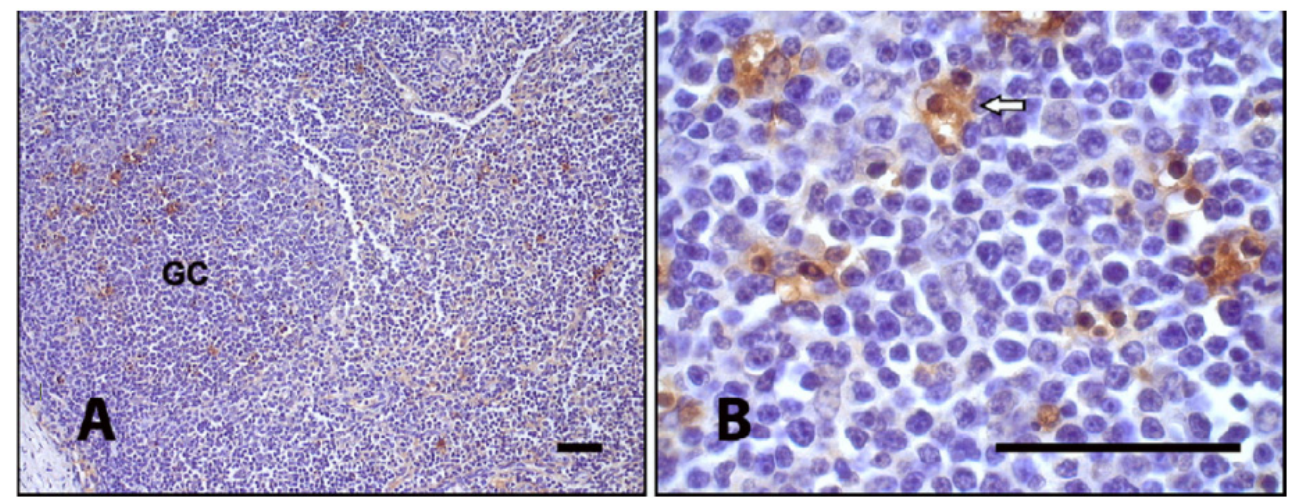

Figure 2. Microphotography of bovine lymph nodes. (A) TUNEL-positive cells in the dark zone of germinal center (GCs). (B) Arrow shows details of TUNEL-positive cells 7 days after immunization. Scale bar $50 \mathrm{~mm}$.

\section{Concluding remarks}

Much progress has been made over the past 15 years analyzing cell death in the immune system. Many cell death regulators have been discovered and their functions defined in experiments with transgenic and knockout mice. In the immune system, apoptosis is seen in cells that are stressed or deprived of growth factors, in developing cells that fail to properly rearrange an antigen receptor or express one that fails negative or positive selection, or in 
cells that had expanded in response to an antigenic stimulus and are now in excess. We observed that the repeated stimulation of $T$ cells previously activated with synthetic vaccine triggers AICD. Secondary lymphoid organs such as the spleen and lymph nodes provide the critical niches where naïve B cells encounter antigens and produce high-affinity antibodies. Many recent avenues of investigation have elucidated that the germinal center is a dynamic microenvironment where B-cells undergo repeated rounds of mutation and selection. The complex microarchitecture of the germinal center is therefore created not only by distinct stages of B-cell maturation but also by the distribution of immunophenotypically distinct and functionally specialized $\mathrm{T}$, dendritic, and stromal cell subpopulations and their myriad interactions. The GC response is a complex process involving numerous cellular and cell surface components together with multiple signaling pathways. Recent advances in the field include a better understanding of the role of follicular dendritic cells, chemokines and TNF family members in forming and maintaining GC reactions. Even with these new advances, much remains to be understood in GC biology. Not only is there little understanding of the mechanisms that regulate and control GC B cell differentiation, but efforts need to be focused on examining abnormal GC responses, especially in the setting of autoimmunity

\section{Author details}

Joaquín H. Patarroyo S.

Laboratory of Biology and Control of Hematozoa and Vectors, BIOAGRO/Veterinary Department - Federal Viçosa University Viçosa-MG, Brazil

Marlene I. Vargas V.

Laboratory of Immunopathology,

BIOAGRO/Veterinary Department - Federal Viçosa University Viçosa-MG, Brazil

\section{References}

[1] Kerr JF, Wyllie AH, Currie AR. (1972) Apoptosis: A basic biological phenomenon with wide-ranging implications in tissue kinetics. Brit. J. Cancer, 26:239-257.

[2] Galluzzi L, Maiuri MC, Vitale I, Zischka H, Castedo M, Zitvogel L, Kromer G. (2007) Cell death modalities: classification and pathophysiological implications. Cell Death and Differentiation, 14: 1237-1266.

[3] Galluzzi L, Vitale I, Abrams JM, Alnemri ES, et. al. (2011) Molecular definitions of cell death subroutines: recommendations of the Nomenclature Committee on Cell Death 2012. Cell Death and Differentiation, 1-14.

[4] Degterev A, Junying Y. (2008) Expansion and evolution of cell death programmes. Cell, 138(2): 229-232.

[5] Lockshin RA, Williams CM. (1965) Programmed cell death. I. Cytology of degeneration in the intersegmental muscles of the pernyi silkmoth. J. Insect Physiol., 11:123-133.

[6] Lockshin RA, Zakeri Z. (2001) Programmed cell death and apoptosis: origins of the theory. Nat. Rev. Mol. Cell Biol., 2:545-550. 
[7] Tamaoki T, Nakano H. (1990) Potent and specific inhibitors of protein kinase C of microbial origin. Bio Technology, 8:732-735.

[8] Cohen JJ, Duke RC (1992) Apoptosis and programmed cell death in immunity. Annu. Rev. Immunol., 10:267-93.

[9] Alnemri ES, Livingston DJ, Nicholson DW, Salvesen G, Thornberry NA, Wong WW, Yuan J. (1996) Human ICE/ CED-3 protease nomenclature. Cell, 87:171.

[10] Cardone M H, Roy N, Stennicke H R, Salvensen G S, Franke T F, Stanbridge E, Frisch S, Reed JC. (1998) Regulation of cell death protease caspase-9 by phosphorylation. Science, 282:1318-1321.

[11] Crabtree GR (1989) Contingent genetic regulatory events in T lymphocyte activation. Science, 243:355-361.

[12] Kroemer G, Galluzzi L, Brenner C. (2007) Mitochondrial Membrane Permeabilization in Cell Death. Physiol. Rev., 87:99-163.

[13] Strasser A, Bouillet P. (2003) Apoptosis regulation in lymphocyte development, Immunological Reviews, 193:82-92.

[14] Marsden VS, Strasser A (2003) Control of Apoptosis in the Immune System: Bcl-2, BH3Only Proteins and More. Annu. Rev. Immunol., 21:71-105.

[15] Tait SWG, Green DR. (2010) Mitochondria and cell death: outer membrane permeabilization and beyond. Nature Rev., 11:621-632.

[16] Logue SE, Martin SJ. (2008) Caspase activation cascades in apoptosis. Biochem. Soc. Trans., 36(Pt 1):1-9.

[17] Nakagawa T, Zhu H, Morishima N, Li E, Xu J, Yankner B A, Yuan J. (2000) Caspase-12 mediates endoplasmic reticulum-specific apoptosis and cytotoxicity by amyloid beta. Nature, 403:98-103.

[18] Jäättella M, Tschopp J. (2003) Caspase-independent cell death in T lymphocytes. Nature immunology, 4:416-422.

[19] Kang MH, Reynolds CP (2009) Bcl-2 Inhibitors:targeting mitochondrial apoptotic pathways in cancer therapy. Clin. Cancer Res.,15(4):1126-1132.

[20] Igney FH, Krammer PH. (2002) Death and anti-death: tumour resistance to apoptosis. Nat. Rev. Cancer, 2:277-288.

[21] Marsden V (2002) Apoptosis initiated by Bcl-2- regulated caspase activation independently of the cytochrome $c /$ Apaf-1/caspase-9 apoptosome. Nature, 419:634-637.

[22] Elmore S. (2007) Apoptosis: A Review of programmed cell death. Toxicol. Pathol., 35(4):495-516.

[23] Wallach D, Kovalenco AV, Varfolomeev EE, Boldin MP. (1998) Death-inducing fuctions of ligands of the tumor necrosis factor family: a Sanhedrib verdict. Current Opinion in Immunology, 10:279-288.

[24] Salvensen G S, Dixit, VM. (1997) Caspases: Intracellular signaling by proteolysis. Cell, 91:443-446.

[25] Green DR, Reed JC (1998) Mitochondria and apoptosis. Science, 281:1309-1312.

[26] Reed JC. (2000) Warner Lambert/Parke Davis award lecture: mechanisms of apoptosis. American Journal of Pathology, 157:1415-1430.

[27] Hengartner M, Ellis RE, Horvitz HR. (1992) Caenorhabditis elegans gene ced-9 protects cells from programmed cell death. Nature, 356:494-499. 
[28] Evan GI, Wyllie AH, Gilbert CS, Littlewood TD, Land H, Brooks M, Waters CM, Penn LZ, Hanccock DC. (1992) Induction of apoptosis in fibroblasts by c-myc protein. Cell, 69:119-128.

[29] Thornberry N, Lazebnik Y. (1998) Caspases: enemies within. Science, 281, 1312-1316.

[30] Nicholson W. (1999) Caspase structure, proteolytic substrates, and function during apoptotic cell death. Cell Death Differ., 6:1028-1042.

[31] Martinvalet D, Zhu P, Lieberman J (2005) Granzyme A induces caspase- independent mitochondrial damage, a required first step for apoptosis. Immunity, 22:355-70.

[32] Lassus P, Opitz-Araya X, Lazebnik Y. (2002) Requirement for caspase-2 in stressinduced apoptosis before mitochondrial permeabilization. Science, 297:1352-1354.

[33] Pistritto G, Jost M, Srinivasula SM, Baffa R, Poyet JL, Kari C, Lazebnik Y, Rodeck U, Alnemri ES. (2002) Expression and transcriptional regulation of caspase-14 in simple and complex epithelia. Cell Death Differ. 9:995-1006.

[34] Koenig U, Eckhart L, Tschachler E. (2001) Evidence that Caspase-13 is not a human but a bovine gene. Biochem. Biophys. Res. Commun., 285:1150-1154.

[35] Wajant H (2002) The Fas Signaling Pathway: More than a paradigm. Science, 296(5573):1635-1636.

[36] Wajant H (2003) Death receptors. Essays Biochem., 39:53-71.

[37] Gupta S (1996) Apoptosis/Programmed Cell Death: A historical Perspective. In: P. Press (Ed.) Mechanisms of lymphocyte Activation and Immune Regulation VI, Vol. 406. Plenum Publishing Corporation, New York, p. 270.

[38] Csiszár Á. (2006) Structural and functional diversity of adaptor proteins involved in tyrosine kinase signalling. BioEssays, 28(5):465-479.

[39] Ulukaya E, Acilan C, Yilmaz Y. (2011) Apoptosis: why and how does it occur in biology? Cell Biochem. Funct., 29:468-480.

[40] Peter ME, Krammer PH. (1998) Mechanisms of CD95 (APO-1/Fas) mediated apoptosis. Current Opinion Immunology, 10:545-551.

[41] Green DR, Droin N, Pinkoski M. (2003) Activation-induced cell death in T cells. Immunological Rev., 193:70-81.

[42] Degterev A, Boyce M, Yuan J. (2003) A decade of caspases. Oncogene, 22, 8543-8567.

[43] Degli-Esposti, M. (1999) To die or not to die-the quest of the TRAIL receptors. J. Leukoc. Biol., 65:535-542.

[44] Pan G, O'Rourke K, Chinnaiyan AM. (1997) The receptor for the cytotoxic ligand TRAIL. Science, 276:111-113.

[45] Ashkenazi, A., Dixit VM. (1998) Death receptors: signaling and modulation. Science, 281:1305-1308.

[46] Suliman A, Lam A, Datta R, Srivastava RK. (2001) Intracellular mechanisms of TRAIL: apoptosis through mitochondrial-dependent and -independent pathways. Oncogene, 20:2122-2133.

[47] Budihardjo I, Oliver H, Lutter M, Luo X, Wang X. (1999) Biochemical pathways of caspase activation during apoptosis. Annu. Rev. Cell Dev. Biol., 15, 269-290.

[48] Hunot S, Flavell RA. (2001) Apoptosis. Death of a monopoly? Science, 292: 865-866.

[49] Von Ahsen O, Renken C, Perkins G, Kluck RM, Bossy-Wetzel E, Newmeyer DD (2000) Preservation of mitochondrial structure and function after Bid- or Bax mediated cytochrome c release. J Cell Biol 150:1027-1036. 
[50] Chipuk JE, Kuwana T, Bouchier-Hayes L. (2004) Direct activation of Bax by p53 mediates mitochondrial membrane permeabilization and apoptosis. Science, 303:1010-1014.

[51] Daniel PT, Krammer PH. (1994) Activation induces sensitivity toward APO-1 (CD95)mediated apoptosis in human B cells. J. Immunol., 152:5624-5632.

[52] Opferman JT, Korsmeyer SJ. (2003) Apoptosis in the development and maintenance of the immune system. Nature immunology, 4(5):410-415.

[53] Hengartner MO. (2000) The biochemistry of apoptosis. Nature, 407(6805):770-776.

[54] Finkel E. (2001) The mitochondrion: Is it central to apoptosis. Science, 292(5517):624-626.

[55] Srinivasula SM, Hegde R, Saleh A. (2001) A conserved XIAP-interaction motif in caspase9 and Smac/DIABLO regulates caspase activity and apoptosis. Nature, 410:112-116.

[56] Krammer PH (2000) CD95's deadly mission in the immune system. Nature, 407:789-795.

[57] Adams JM. (2003) Ways of dying: multiple pathways to apoptosis. Genes Dev., 17:2481-24.

[58] Czerski L, Nunes G. (2004) Apoptosome formation and Caspase activation: is it different in the heart. J. Mol. Cell Cardiol., 37(3):643-652.

[59] O'Brien Mauria A, Kirby R. (2008) Apoptosis: A review of pro-apoptotic and anti-apoptotic pathways and dysregulation in disease. J. Vet. Emerg. Crit. Care, 18(6):572-585.

[60] Zimmermann KC, Green DR. (2001) How cells die: apoptosis pathways. J. Allergy Clin. Immunol., 108(Suppl 4):S99-S103.

[61] Fesik SW, Shi Y. (2001) Controlling the Caspases. Science, 294(5546):1477-1478.

[62] Kang MH, Reynolds CP. (2009) Bcl-2 Inhibitors:Targeting Mitochondrial Apoptotic Pathways in Cancer Therapy Clin. Cancer Res.,15(4):1126-1132.

[63] Packham G, Stevenson FK (2005) Bodyguards and assassins: Bcl-2 family proteins and apoptosis control in chronic lymphocytic leukemia. Immunology, 114:441-449.

[64] Youle, R J. Strasser A. (2008) The BCL-2 protein family: opposing activities that mediate cell death. Molecular Cell Biology, 9:47- 59.

[65] Power C, Fanning N, Redmond (2002) Cellular apoptosis and organ injury in sepsis: a review. Shock 18(3):197-211.

[66] Hakem R, et al (1998) Differential requirement for caspase 9 in apoptotic pathways in vivo. Cell, 94:339-352.

[67] Gupta S. (2005) Molecular mechanisms of apoptosis in the cells of the immune system in human aging. Immunol. Rev., 205:114-129.

[68] Zakeri Z, Lockshin RA. (2008) Cell death: history and future. Adv. Exp. Med. Biol., 615:11.

[69] Haupt S, Berger M, Goldberg Z, Haupt Y. (2003) Apoptosis the p53 network. J. Cell Sci., 116(Pt20):4077-4085.

[70] Jameson SC, Hogquist KA, Bevan MJ. (1995) Positive selection of thymocytes. Annu. Rev. Immunol., 13:93-126.

[71] Ashton-Rickardt PG, Tonegawa S. (1994) A differential-avidity model for T-cell selection. Immunol.Today, 15:362-366.

[72] Von Boehmer H. (1992) Thymic Selection: A Matter of Life and Death. Immunol. Today, 13:454-458.

[73] Owen JJ, Jenkinson EJ (1992) Apoptosis and T-cell repertoire selection in the thymus. Ann. NY Acad. Sci., 663:305-310.

[74] Harris SL, Levine AJ. (2005) The p53 pathway: positive and negative feedback loops. Oncogene, 24: 2899-2908. 
[75] Krammer PH, Behrmann I, Daniel P, Dhein J, Debatin KM. (1994) Regulation of apoptosis in the immune system. Current Opinion in Immunology, 6:279-289.

[76] Scaffidi C, Kirchhoff S, Krammer PH, Peter ME. (1999) Apoptosis signaling in lymphocytes. Current Opinion immunology, 11:277-285.

[77] Sebzda E, Mariathasan S, Ohteki T, Jones R, Bachmann MF, Ohashi O (1999) Selection of the T Cell Repertoire. Annual Review of Immunology 17: 829-874.

[78] Berzins SP, Godfrey DI, Miller JFAP, Boyd RL. (1999) A central role for thymic emigrants in peripheral T cell homeostasis. Proc. Natl. Acad. Sci. USA, 96:9787-9791.

[79] Krammer, P. H. (1999) CD95(APO-1/Fas)-mediated apoptosis: live and let die. Adv. Immunol., 71:163-210.

[80] Xu G, Yufang S. (2007) Apoptosis signaling pathways and lymphocyte homeostasis. Cell Research 17(9):759-771.

[81] Zhang N, Hartig H, Dzhagalov I, Draper D, HE YW (2005) The role of apoptosis in the development and function of T lymphocytes. Cell Research, 15(10):749-769

[82] Egerton M, Scollary R, Shortman K. (1990) Kinetic of mature T cell development in the thymus. Proc. Natl. Acad. Sci.USA, 87:2579-2582.

[83] Surth CD, Sprent J. (1994) In situ detection of T-cell apoptosis during positive and negative selection in the thymus. Nature, 372:100-103.

[84] Norbury CJ, Hickson ID. (2001) Cellular responses to DNA damage. Annu. Rev. Pharmacol. Toxicol., 41:367-401.

[85] Strasser A, Pellegrini M. (2004) T-lymphocyte death during shutdown of an immune response. Trends in Immunology, 25(11):610-615.

[86] Osmond DG, Kim N, Manoukian R, Phillips RA, Rico-Vargas SA, Jacobsen K. (1992) Dynamics and localization of early B-lymphocyte precursor cells (pro-B cells) in the bone marrow of scid mice. Blood, 79:1695-1703

[87] Krammer PH, Dhein J, Walczak H, Behrmann I, Mariani S, Matiba B, Fath M, Daniel PT, Knipping E, Westendorp MO, Stricker K, Bäumler C, Hellbardt S, Germer M, Peter ME and, Debati KM. (1994) The Role of APO-1-Mediated Apoptosis in the Immune System. Immunological Reviews, 142(1):175-191.

[88] Singer GG, Abbas AK. (1994) The Fas antigen is involved in peripheral but not thymic deletion of T lymphocytes in T cell receptor transgenic mice. Immunity, 1(5): 365-371.

[89] Kabelitz D, Pohl T, Pechhold K. (1993) Activation-induced cell death (apoptosis) of mature peripheral T lymphocytes. Immunol. Today, 14:338-339.

[90] Green D R, Scott DW. (1994) Activation-induced apoptosis in lymphocytes. Current Opinion in Immunology, 6:476-487.

[91] Jones LA, Chin LT, Longo DL, Kruisbeek AM. (1990) Peripheral clonal elimination of functional T cells. Science. 250:1726-1729.

[92] Newell MK, Haughn LJ, Maroun CR, Julius MH. (1990) Death of mature cells by separate ligation of CD4 and the T-cell receptor for antigen. Nature, 347:286-289.

[93] Wesselborg S, Janssen O, Kabelitz D. (1993) Induction of activation-driven death (apoptosis) in activated but not resting peripheral blood T cells. J. Immunology, 150:4338-4345.

[94] Thome M, Schneider P, Hofman NK, Fickenscher H, Meinl E, Neipel F, Mattmann C, Burns K, Bodmer JL, Schroter M, Scaffifidi C, Krammer PH, Peter ME, Tschopps J. 
(1997) Viral FLICE-inhibitory proteins (FLIPs) prevent apoptosis induced by death receptors. Nature, 386:517-521.

[95] Janssen O, Qian J, Linkermann A, Kabelitz D. (2003) CD95 ligand - death factor costimulatory molecule? Cell Death Differ. 10:1215-1225.

[96] Janssen O, Sanzenbacher R, Kabelitz D. (2000) Regulation of activation-induced cell death of mature T-lymphocyte populations. Cell Tissue Res., 301:85-99.

[97] Hildeman DA, Zhu Y, Mitchel TC, Kappler J, Marrack P. (2002) Molecular mechanisms of activated $\mathrm{T}$ cell death in vivo. Current Opinion in Immunology, 14:354-359.

[98] Zhang N, Hartig H, Dzhagalov I, Draper D, Wen HE. (2005) The role of apoptosis in the development and function of T lymphocytes. Cell Res., 15(10):749-769.

[99] Ruiz-Ruiz MC, Oliver FJ, Izquierdo M, López-Rivas A. (1995) Activationinduced apoptosis in Jurkat cells through a myc-independent mechanism. Molecular Immunology, 32(13):947-955.

[100] Alam A, Cohen LY, Aouad S, Sekaly RP. (1999) Early activation of caspases during T lymphocyte stimulation results in selective substrate cleavage in nonapoptotic cells. J. Exp. Medical. 190:1879-1890.

[101] Yonehara S, Ishii A, Yonehara M. (1989) A cell-killing monoclonal antibody (anti-Fas) to a cell surface antigen co-downregulated with the receptor for tumor necrosis factor. J. Exp. Med., 169:1747-1756.

[102] Trauth BC, Klas C, Peters AM, Matzku S, Möller P, Falk W, Debatin KM, Krammer PH. (1989) Monoclonal antibody-mediated tumor regression by induction of apoptosis. Science, 245:301-305.

[103] Bajorath J, Aruffo A (1997) Prediction of the three-dimensional structure of the human Fas receptor by comparative molecular modeling. J. Comput. Aided. Mol. Des., 11:3-8.

[104] Callard R, Hodgkin P (2007) Modeling T- and B-cell growth and differentiation. Immunological Reviews, 216:119-129.

[105] Malissen B, Malissen M. (1996) Functions of TCR and pre-TCR subunits: lessons from gene ablation. Current Opinion Immunol., 8:383-393.

[106] Samelson LE, Phillips AF, Luong ET, Klausner RD. (1990) Association of the fyn proteintyrosine kinase with the T-cell antigen receptor. Proc. Natl. Acad. Sci. USA, 87: 4358-4362.

[107] Klausner RD, Patel MD, O'Shea JJ, Samelson LE. (1987) Phosphorylation of the T cell antigen receptor: multiple signal transduction pathways. J. Cell Physiol. Suppl., 5:49-51.

[108] Thorburn A. (2004) Death receptor-induced cell killing. Cell Signal, 16, 139-144.

[109] Alberola-Ila J, Takaki S, Kerner JD, Perlmutter RM (1997) Differential signaling by lymphocyte antigen receptors. Annual Rev. Immunol., 15:125-154.

[110] O'Reilly LA, Tai L, Lee L, Kruse EA, Grabow S, Fairlie WD, Haynes NM, Tarlinton DM, Zhang JG, Belz GT, Smyth MJ, Bouillet P, Robb L, Strasser, A. (2009) Membranebound Fas ligand only is essential for Fas-induced apoptosis. Nature, 461:659-663.

[111] Dhein J, Walczak, Baumler C, Debatin KM, Krammer, PH. (1995) Autocrine T-cell suicide mediated by APO-1/(Fas/CD95). Nature, 373:438-441.

[112] Paulsen M, Valentin S, Mathew B, Adam-Klages S, Bertsch U, Lavrik I, Krammer PH, Kabelitz D, Janssen O. (2010) Modulation of CD4+ T cell activation by CD95 costimulation. Cell Death Differ., doi:10.1038/cdd.2010.134 
[113] Lettau M, Paulsen M, Schmidt H, Janssen O. (2011) Insights into the molecular regulation of FasL (CD178) biology. Eur J. Cell Biol., 90:456-466.

[114] Tourneur L, Chiocchia G. (2010) FADD: a regulator of life and death. Trends in Immunology, 31(7):260-269.

[115] Krammer PH, Arnold R, Lavrik IN. (2007) Life and death in peripheral T cells. Nature Rev. Immunol 7: 532-542.

[116] Okada T, Cyster JG. (2006) B cell migration and interactions in the early phase of antibody responses. Current Opinion in Immunology 18:1-8.

[117] Tarlinton DM, and. Smith KGC. (2000) Dissecting affinity maturation: a model explaining selection of antibody-forming cells and memory B cells in the germinal center. Immunol. Today, 21:436.

[118] Lindhout E, Koopman G, Pals ST, Groot de C (1997) Triple check for antigen specificity of $B$ cells during germinal center reactions. Immunol. Today, 18:573.

[119] Sixt M, Kanazawa N, Selg M, Samson T, Roos G, Reinhardt DP, Pabst R, Lutz MB, Sorokin L. (2005) The conduit system transports soluble antigens from the afferent lymph to resident dendritic cells in the T cell area of the lymph node. Immunity, 22:19-29.

[120] Vikstrom I, Tarlinton DM (2011) B cell memory and the role of apoptosis in its formation. Molecular Immunology 48:1301-1306.

[121] MacLennan IC, Toellner KM, Cunningham AF, Serre K, Sze DM, Zuniga E, Cook MC, Vinuesa CG (2003) Extrafollicular antibody responses. Immunol. Rev.,194:8-18.

[122] Liu YJ, Joshua DE, Williams GT, Smith CA, Gordon J, Maclennan IC. (1989) Mechanism of antigen-driven selection in germinal centers. Nature, 342:929-931.

[123] Batista FD, Harwood NE. (2009) The who, how and where of antigen presentation to B cells. Nature Reviews Immunology 9:15-27.

[124] Manceney M, Richard Y, Colaud D, Tursz T, Wiew J (1991) CD77: an antigen of germinal center B cells entering apoptosis. J. Immunol, 21:1131-1140.

[125] Liu YJ, Cairns JA, Holder MJ, Ahrot SD, Jansen KU, Bonnefoy JY, Gordon J, Maclennan IC. (1991) Recombinant 25-kDa CD23 and Interleukin 1 promote the survival of germinal center B: Evidence for bifurcation in the development of centrocytes rescued from apoptosis. Eur. J. Immunol, 21:1107-1114.

[126] Kuklina E M, Shirshev SV. (2001) Role of transcription factor NFAT in the immune response. Biochemistry (Moscow), 66(5): 467-475.

[127] Hehlgans T, Pfeffer K. (2005) The intriguing biology of the tumour necrosis factor/tumour necrosis factor receptor superfamily: players, rules and the games. Immunology. 115(1):1-20.

[128] Yang E, Zha J, Jockel J, Korsmeyer SJ. (1995) Bad: a heterodimeric partner of Bcl-xL and Bcl-2, displaces Bax and promotes cell death. Cell, 80:285-291

[129] Kondo M, Akashi K, Domen J, Sugamura K, Weissman IL. (1997) Bcl-2 Rescues T lymphopoiesis, but not B or NK cell development, in common $\gamma$ Chain-deficient mice. Immunity, 7 (1):155-162.

[130] Strasser A, Harris AW, Huang DCS, Krammer PH, Cory S. (1995) Bcl-2 and Fas/APO-1 regulate distinct pathways to lymphocyte apoptosis. EMBO J, 14:6136-6147.

[131] Kearney ER, Pape KA, Lo DY, Jenkins MK (1994) Visualization of peptide-specific T cell immunity and peripheral tolerance induction in vivo. Immunity, 1(4): 243-339. 
[132] Maclennan IC, Liij YJ, John GD. (1992) Maturation and dispersal of B-Cell clones during T cell-dependent antibody responses. Immunol. Rev., 126:143-161.

[133] Strasser A. (1995) Life and death during lymphocyte development and function: evidence for two distinct killing mechanisms. Current Opinion Immunol., 7:228-234.

[134] Lassus P, Opitz-Araya X and Lazebnik Y. (2002) Requirement for caspase-2 in stressinduced apoptosis before mitochondrial permeabilization. Science, 297:1352-1354.

[135] MacLennan IC; Liu YJ; Oldfield S; Zhang J; Lane PJ. (1990) The evolution of B-cell clones. Current topics in Microbiology and Immunology,159:37-63.

[136] Nutt SL, Tarlinton DM. (2011) Germinal center B and follicular helper T cells: siblings, cousins or just good friends? Nature Immunology, 12:472-477.

[137] Chen A, Zheng G, Tykocinski ML. (2003) Quantitative interplay between activating and pro-apoptotic signals dictates $\mathrm{T}$ cell responses. Cellular Immunology, 221:128-137.

[138] Lenardo M, Chan KM, Hornung F, et al. (1999) Mature T lymphocyte apoptosisimmune regulation in a dynamic and unpredictable antigenic environment. Annu. Rev. Immunol., 17:221-253.

[139] Van Parijs L, Refaeli Y, Lord J, Nelson BH, Abbas AK, Baltimore D. (1999) Uncoupling IL-2 signals that regulate T cell proliferation, survival, and Fas mediated activationinduced cell death. Immunity, 11:281-288.

[140] Schmitz I, Krueger A, Baumann S, Schulze-Bergkamen H, Krammer PH, Kirchhoff S. (2003) An IL-2-dependent switch between CD95 signaling pathways sensitizes primary human $\mathrm{T}$ cells toward CD95-mediated activation-induced cell death. J. Immunol., 171(6):2930-2936.

[141] Refaeli Y, Van Parijs L, London CA, Tschopp J, Abbas AK. (1998) Biochemical mechanisms of IL-2- regulated Fas-mediated T cell apoptosis. Immunity, 8: 615-623.

[142] Sytwu HK, Liblau RS, McDevitt HO. (1996) The roles of Fas/APO-1 (CD95) and TNF in antigen-induced programmed cell death in $\mathrm{T}$ cell receptor transgenic mice. Immunity, 5:17-30.

[143] Janssen EM, Droin NM, Lemmens EE, Pinkoski MJ, Bensinger SJ, Ehst BD, Griffith TS, Green DR, Schoenberger SP (2005) CD4+ T-cell help controls CD8+ T-cell memory via TRAIL-mediated activation-induced cell death. Nature, 434:88-93.

[144] Martínez-Lorenzo MJ, Alava MA, Gamen S, Kim KJ, Chuntharapai A, Pineiro A. (1998) Involvement of APO2 ligand TRAIL in activation-induced death of Jurkat and human peripheral blood T cells. Eur. J. Immunol. 28:2714-2725.

[145] Devadas S, Das J, Liu C, Zhang L, Roberts, Pan Z, Moore PA, Gobardhan D. (2006) Granzyme B is critical for T cell receptor-induced cell death of type 2 helper T cells. Immunity 25:237-247.

[146] Lenardo MJ. (1991) lnterleukin-2 programs mouse $\alpha \beta$ T lymphocytes for apoptosis. Nature 353, 858-861.

[147] Patarroyo JH, Vargas MI , González CZ , Guzmán F , Martins-Filho OA, Afonso LCC, Valente FL, Peconick AP, Marciano AP, Patarroyo AM V, Sossai S. (2009) Immune response of bovines stimulated by synthetic vaccine SBm7462 against Rhipicephalus (Boophilus) microplus. Vet. Parasitol. 166:333-339. 